\title{
A cross-sectional study to determine the energy density and nutritional quality of primary-school children's lunchboxes
}

\author{
Rachel Sutherland ${ }^{1,2,3,4, *}$, Nicole Nathan 1,2,3,4, Alison Brown 1,2,3,4, Serene Yoong 1,2,3,4, \\ Renee Reynolds ${ }^{1,2}$, Alison Walton 1, Lisa Janssen ${ }^{1}$, Clare Desmet $^{1,2}$, \\ Christophe Lecathelinais ${ }^{1,2,3,4}$, Karen Gillham 1, Vanessa Herrmann' and \\ Luke Wolfenden ${ }^{1,2,3,4}$ \\ 'Hunter New England Population Health, Locked Bag 10, Wallsend, NSW 2287, Australia: ${ }^{2}$ School of Medicine and \\ Public Health, University of Newcastle, Callaghan, New South Wales, Australia: ${ }^{3}$ Hunter Medical Research Institute, \\ New Lambton Heights, New South Wales, Australia: ${ }^{4}$ Priority Research Centre for Heath Behaviour, University of \\ Newcastle, Callaghan, New South Wales, Australia
}

Submitted 11 December 2018: Final revision received 23 July 2019: Accepted 30 July 2019: First published online 23 January 2020

\begin{abstract}
Objective: The present study describes the energy content of primary-school children's lunchboxes and the proportion of lunchbox foods considered discretionary. Subgroup analyses by sex, socio-economic status, age and weight status were undertaken.

Design: A cross-sectional study was conducted. Mean kilojoule content, number of items and categorisation of foods and drinks in lunchboxes as 'everyday' (healthy) or discretionary (sometimes) foods were assessed via a valid and reliable lunchbox observational audit.

Setting: Twelve Catholic primary schools (Kindergarten-Grade 6) located in the Hunter region of New South Wales, Australia.

Participants: Kindergarten to Grade 6 primary-school students.

Results: In total, 2143 children (57\%) had parental consent to have their lunchboxes observed. School lunchboxes contained a mean of $2748 \mathrm{~kJ}$, of which $61.2 \%$ of energy was from foods consistent with the Australian Dietary Guidelines and $38.8 \%$ of energy was discretionary foods. The proportion of lunchboxes containing only healthy foods was $12 \%$. Children in Kindergarten-Grade 2 packed more servings of 'everyday' foods $(3.32 v .2 \cdot 98, P<0.01)$ compared with children in Grades 3-6. Children in Grades 3-6 had a higher percentage of energy from discretionary foods $(39.1 v .33 .8 \%, P<0.01)$ compared with children in Kindergarten-Grade 2 and children from the most socio-economically disadvantaged areas had significantly higher total kilojoules in the school lunchbox compared with the least disadvantaged students (2842v. $2544 \mathrm{~kJ}, P=0.03)$.

Conclusions: Foods packed within school lunchboxes may contribute to energy imbalance. The development of school policies and population-based strategies to support parents overcome barriers to packing healthy lunchboxes are warranted.
\end{abstract}

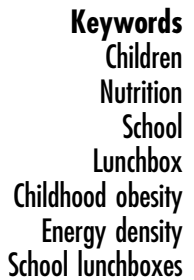

Internationally, population rates of obesity in children and adolescents have increased over the past 40 years $^{(1)}$. In Australia, approximately $25 \%$ of children aged 5-17 years are overweight or obese ${ }^{(2)}$. Unhealthy weight gain in children and adolescents is linked to a number of chronic diseases including type 2 diabetes, CVD and some cancers $^{(2,3)}$. As weight loss and maintenance are difficult to achieve and as obesity tracks from childhood into adulthood $^{(2,4)}$, the prevention of child overweight and obesity is a global public health priority.

Poor dietary intakes of children are a major factor contributing to unhealthy weight ${ }^{(5)}$. Internationally, population-based monitoring surveys have identified that the dietary intakes of children and adolescents do not align with international and national dietary guidelines ${ }^{(6,7)}$. The 2007-2010 National Health and Nutrition Survey 
conducted in the USA reported that children do not meet the recommendations for daily consumption of vegetables or dairy, while exceeding guidelines for added sugar and saturated fats ${ }^{(7)}$. Likewise, National Diet and Nutrition Surveys in the UK highlight that children in Grades 5-6 are not meeting daily recommendations ${ }^{(6)}$. At the same time, longitudinal research indicates that there has been a significant increase in energy intake derived from discretionary snacks (i.e. those foods higher in fat, salt or sugar with little nutritional value ${ }^{(8)}$ ) per capita between 1977 and $2014^{(9)}$. Higher consumption of discretionary foods can result in higher energy intake which is a major driver for excessive weight gain. As good nutrition is considered one of the most important determinants of health and well-being, including the prevention of obesity in children and adolescents ${ }^{(10)}$, strategies that reduce the consumption of discretionary foods consistent with dietary recommendations are needed.

Children spend a considerable portion of their day within the school setting and should consume approximately one-third of their dietary requirements within these hours ${ }^{(5)}$. While the context of school food provision differs internationally, within Australia the school lunchbox is the most important source of food consumed throughout the school day, with more than $85 \%$ of children reporting they bring a packed lunchbox from home ${ }^{(5)}$. Despite this, there are limited recent data detailing the types of foods packed in children's lunchboxes at school. Studies conducted more than a decade ago within Australia concluded that energy-dense foods and beverages were over-represented in Australian schools ${ }^{(5)}$ with the average lunchbox containing over $3000 \mathrm{~kJ}$ and approximately $3 \cdot 1$ servings of discretionary foods ${ }^{(11)}$. Further research conducted in 2010 with 170 Australian school-aged children found that the provision of energy-dense, nutrient-poor snacks was common in lunchboxes, with over $28 \%$ of lunchboxes containing two or more discretionary food servings ${ }^{(12)}$. Similar research conducted in the UK in 2010 involving 1294 children aged 8-9 years found that children's packed lunches were low in fruit and vegetables and the majority contained discretionary choices such as savoury snacks and confectionery ${ }^{(13)}$. Importantly, little is known about differences in the nutritional profile of lunchboxes by age, sex, socioeconomic status (SES) and weight status. Given its overall contribution to child diet, understanding the current nutrition profile of children's school lunchboxes, and how this may differ based on demographic, SES and weight status characteristics, is needed to support the development of targeted school-based public health strategies to improve child nutrition.

The present study aimed to describe the total lunchbox content and mean daily kilojoule content of primary-school children's lunchboxes. In addition, the nutritional quality of lunchboxes was assessed by determining the proportion of lunchbox items classified as 'everyday' healthy food items and the proportion classified as discretionary items, those that are higher in fat, sugar and salt and contributing minimal nutrients to a healthy diet. The study also aimed to identify if there is an association between the energy content and nutritional quality of lunchbox foods and sex, SES, age or weight status.

\section{Methods}

\section{Study design and setting}

A cross-sectional study of children of primary-school age was conducted in twelve Catholic primary schools located in the Hunter region of New South Wales, Australia. The Hunter region encompasses major city and regional areas and is characterised by a higher proportion of the population from low socio-economic backgrounds ${ }^{(14)}$. The research was conducted and reported in accordance with the requirements of the Strengthening the Reporting of Observational Studies in Epidemiology (STROBE) Statement for cross-sectional studies ${ }^{(15)}$ and forms the baseline of a four-armed trial which aims to promote physical activity and nutrition in primary schools.

\section{Sample and participants}

Schools

Catholic primary schools were considered eligible for inclusion if they had greater than 120 student enrolments; were current users of a school mobile communication app (Skoolbag); and were not participating in other nutritionbased research studies. Secondary schools catering for students aged 13-18 years and schools catering for children with special needs (such as intellectual disabilities) were excluded ( $n 28)$. Twelve Catholic primary schools in the study region were randomly selected from publicly available lists to participate in the trial.

\section{Students}

All parents with a child enrolled in Kindergarten to Grade 6 were invited to participate in the study. Active parental consent was required for child participation.

\section{Recruitment procedures}

Schools

A random number function in Microsoft Excel 2013 was used to determine the order in which the eligible primary schools in the study region were approached to participate. Invitations to participate were sent to the first twelve randomly selected primary schools detailing the study and inviting participation. Experienced health promotion officers contacted principals by telephone one week after the invitation letter was sent to the school and a face-to-face meeting was requested to outline the requirements of the study and request consent. If a selected school declined, 
an additional letter was sent to the next eligible school on the list, until twelve schools accepted the invitation to participate.

\section{Students and parents}

Consistent with evidence-based recruitment strategies trialled in previous studies targeting schools and childcare services $^{(16,17)}$, all students in Kindergarten to Grade 6 in the consenting schools were provided with an information package containing an overview of the study and a consent form for parents seeking consent for their child to participate in the study evaluation measures. Parents of students who had not returned a signed consent form were telephoned by school staff to invite participation in evaluation measures. If verbal consent was gained, a replacement consent form was sent to parents. Student assent was also gained from students on the day of data collection. To assess any impact of selective non-participation, parents who did not consent were asked to provide basic demographic information on a form returned to school or during telephone contact where study participation was invited.

\section{Data collection procedures and measures}

The following data were collected by trained research assistants in February to March 2017.

\section{Lunchbox observation}

Lunchboxes of all consenting students were observed at the start of the school day prior to any food being consumed $^{(18)}$. Students and parents were unaware which day lunchbox observations would occur to prevent changes from what is usually packed in the lunchbox ${ }^{(12)}$. All lunchboxes were given a unique identification number to be displayed during data collection. Students were asked to display their lunchbox on their desk and remove all lids from containers. Packaging was removed by the students on request if an item could not be identified from its outside packet. If items were difficult to identify, students were further asked to explain the food item. As the present study was interested in foods brought from home, students' canteen purchases or orders were not included and students intending to order lunch from the canteen were removed from analysis.

Trained research assistants observed the school lunchboxes and a photograph of each student's lunchbox was taken using a tablet device at $90^{\circ}$ and approximately $20 \mathrm{~cm}$ above the lunchbox to enable analysis of the contents at a later time. Photographs were analysed by trained dietitians using an electronic version of the validated School Food Checklist (SFC) ${ }^{(19,20)}$, a previously developed tool shown to be accurate and reliable to measure energy from foods and beverages for the Australian context. The SFC includes twenty food and beverage categories including main food items such as bread, fast foods and leftovers/mixed dishes; snack items such as noodles, packaged snacks, biscuits and crackers, chocolate and lollies, cheese, eggs, dried fruit and nuts, muesli and fruit bars, cakes and buns, muffins and scones, pastries, desserts, yoghurt, fruit and vegetables; and drinks such as milk, soft drink, water and fruit juice. Foods in each category were included based on the frequency of consumption at school for children aged 5-15 years according to the National Nutrition Survey $1995^{(19)}$ and the average kilojoules per category identified. The SFC was used to identify the total lunchbox contents and food items in the lunchbox, including the kilojoule content and number of 'everyday' or discretionary lunchbox items and the mean cost of lunchbox items (not reported herein). 'Everyday' items refer to food and drink items that are part of the core food groups as determined by the Australian Dietary Guidelines and Australian Guide to Healthy Eating ${ }^{(8)}$. Foods and drinks classified as discretionary choices are items considered to be energy-dense with minimal nutritional value such as cakes, chocolate, lollies, crisps, muesli bars and fast foods.

Minor modifications were made to the SFC to enable foods to be categorised separately as either 'everyday' or discretionary. The mean cost of lunchbox items was also updated to align with costs at the time the study was conducted. Categories that required adjustment included: biscuits and crackers, cakes and buns, muffins and scones, desserts and packaged snacks. All foods in these categories were individually divided and categorised as an 'everyday' or discretionary food by consensus among dietitians. The serving size and kilojoules per serving information were obtained from FoodWorks Professional Edition V7 (Xyris Software, Highgate Hill, QLD, Australia), or if unavailable from FoodWorks, via a snack food database created for pre-packaged items. The snack food database was created by dietitians based on a significant array of pre-packaged snacks available in Australian supermarkets and included detailed nutrition information for each food item.

Based on the size or quantity of a lunchbox item, the number of servings per item was also recorded. A visual serving size guide was used in conjunction with the SFC in order to appropriately determine the serving sizes of popular food items based on standard servings for each food included in FoodWorks Professional Edition V7. Dietitians were trained to classify foods and drinks according to their SFC category and the serving size of each item by observing each school lunchbox photograph. In addition, a set of assumptions was used by dietitians to code school lunchboxes. Assumptions were predetermined prior to data analysis and added to during analysis for any food or beverage items that were ambiguous. This included but was not limited to sandwich fillings, dips and spreads, snack packs, cheese and yoghurt. To minimise variability in assessment, all lunchbox photographs were assessed by two dietitians who worked together to make a consensus decision on the analysis for every lunchbox. Differences in opinion between dietitians were resolved following consultation with a third assessor. 


\section{Student characteristics}

Student sex and school grade were collected for all students from consent forms. Parent postcode, employment status (self-employed, employed for wages, part-time, full time, unemployed, student, retired or other) and highest qualification level (did not complete high school, completed high school, tertiary education or other) were collected from a parent computer-assisted telephone interview of consenting parents. SES was determined using the 2016 Socio-Economic Index for Areas (SEIFA) ${ }^{(21)}$ via parents' postcode and was dichotomised at the New South Wales median into most disadvantaged and least disadvantaged groups accordingly.

\section{Anthropometry}

Due to the measurement burden on the school, height and weight were collected on a sub-sample of all consenting students from Grades 4 to 6 by trained research assistants using procedures of the International Society for the Advancement of Kinanthropometry ${ }^{(22)}$. Measures were taken in light clothing without shoes. Weight was measured using a portable digital scale (model no. DC430MA; Tanita Company Ltd, Tokyo, Japan) to the nearest $0 \cdot 1 \mathrm{~kg}$. Height was recorded to the nearest $0 \cdot 1 \mathrm{~cm}$ using a portable stadiometer (model no. PE087; Mentone Educational Centre, Springvale, Victoria, Australia). Two recordings of height were taken and the average used. Based on measures taken, BMI was calculated as weight/ height squared $\left(\mathrm{kg} / \mathrm{m}^{2}\right)$. Weight status was determined using the International Obesity Taskforce definitions to classify children's weight status as underweight, healthy, overweight or obese ${ }^{(23)}$

\section{Data analysis}

All statistical analyses were performed using the statistical software package SAS version 9.3. All univariate analyses were two-tailed with an $\alpha$ value of $0 \cdot 05$. Summary statistics were used to describe all variables of interest.

For each characteristic (age, sex, BMI and SES), individual linear mixed regression models were used to assess univariate associations with preliminary outcomes related to the mean kilojoules packed in lunchboxes, kilojoules from discretionary foods and percentage of kilojoules from discretionary foods. Individual logistic mixed regression models were also performed to examine univariate associations between student characteristics (sex, SES, school year and BMI) and the odds of having no discretionary foods packed within the lunchbox. All four characteristics (sex, BMI, SES and school year) were also included in multiple mixed-effects regression models to assess their association with preliminary outcomes while adjusting for each other.

All combinations of two-way interactions among characteristics (sex, BMI, SES and school year) were assessed for potential joint effect on outcomes, with
$P<0.01$ considered as significant. All of the aforementioned models included a random effect for school to take account of the potential school-level clustering effect.

\section{Results}

\section{Sample}

Twenty schools were invited to participate in order to obtain twelve consenting schools (60\% consent rate). A total of 3772 students were invited to participate in the lunchbox observation, of which 2143 parents provided consent ( $57 \%$ consent rate). On the day of observation, 1915 students were present. Of 1915 lunchbox observations, 146 were excluded due to students indicating they would be purchasing their main meal from the canteen. The final sample consisted of 1769 children's lunchboxes. Of the consenting and present students, $49 \%$ were female, $69 \%$ were from low socio-economic backgrounds and $43.7 \%$ of children were in Kindergarten to Grade 2 (younger children), with the remaining $56.3 \%$ in Grades 3 to 6 (older children). There were no significant differences in age, sex or SES between those who consented and those who did not consent; however, students in Grade 4 were more likely to consent than other school years (62 v. 53-59\%, $P=0.04)$. The characteristics of the consenting students are listed in Table 1.

\section{Total lunchbox contents}

The mean number of items packed in school lunchboxes was 5.8 (SD 1.7) with a range of 1-16 items. The energy in foods accounted for $85 \%$ of the entire lunchbox and drinks formed $15 \%$ of the energy. Of the foods packed

Table 1 Characteristics of the sample of Kindergarten-Grade 6 primary-school students ( $n$ 1769) from twelve Catholic primary schools located in the Hunter region of New South Wales, Australia, February to March 2017

\begin{tabular}{|c|c|c|}
\hline Characteristic & $n$ or mean & $\%$ or SD \\
\hline \multicolumn{3}{|l|}{ Sex, $n$ and $\%(n 1754)$} \\
\hline Female & 859 & $49 \cdot 0$ \\
\hline Male & 895 & $51 \cdot 0$ \\
\hline Age (years), mean and SD (n1497) & 7.96 & $2 \cdot 0$ \\
\hline \multicolumn{3}{|c|}{ Socio-economic status ${ }^{*}, n$ and $\%(n 1769)$} \\
\hline Most disadvantaged & 1222 & $69 \cdot 1$ \\
\hline Least disadvantaged & 547 & $30 \cdot 9$ \\
\hline \multicolumn{3}{|l|}{ Anthropometric characteristics } \\
\hline Weight $(\mathrm{kg})$, mean and SD $(n 711)$ & 38.72 & $9 \cdot 8$ \\
\hline Height (m), mean and SD (n712) & 1.43 & $0 \cdot 1$ \\
\hline \multicolumn{3}{|c|}{ BMI category ( $n 624 \dagger, 48.72 \%$ male, $51.28 \%$ female) } \\
\hline Age (years), mean and SD & 9.9 & 0.9 \\
\hline Underweight, $n$ and $\%$ & 26 & 4.2 \\
\hline Healthy weight, $n$ and \% & 424 & $68 \cdot 0$ \\
\hline Overweight, $n$ and \% & 135 & $21 \cdot 6$ \\
\hline Obese, $n$ and $\%$ & 39 & $6 \cdot 3$ \\
\hline
\end{tabular}

*Socio-economic status based on the 2016 Socio-Economic Index for Areas (SEIFA) Index of Relative Socio-Economic Advantage/Disadvantage. Most disadvantaged = lowest quartiles of SEIFA; least disadvantaged = highest quartiles of SEIFA. †BMI could not be classified for children missing sex or age. 
within the lunchbox, the mean number of 'everyday' food servings was $3 \cdot 1$ (SD 1.6), while the mean number of discretionary food servings was $2 \cdot 5$ (SD $2 \cdot 1)$. Of the small number of drinks in school lunchboxes, $83 \%$ were categorised as 'everyday' servings, which was predominately water.

On average, bread-based items were the primary lunch item for $81 \%$ of children. The most common snack items were fruit ( $86 \%$ ); sweet snacks categorised as a discretionary food (67\%) such as sweet biscuits, chocolate and lollies, cakes and muesli bars; and savoury snacks categorised as a discretionary food (55\%) such as crisps or chips and savoury biscuits. On average, $20 \%$ of lunchboxes contained vegetables. The food and drink items contained in the lunchboxes are listed in Table 2.

\section{Energy from food and drink servings in scbool lunchboxes}

The mean energy from foods and drinks packed within school lunchboxes was 2748 (sD 882) kJ. Of the $2748 \mathrm{~kJ}$, $61.2 \%$ of energy was provided by foods and drinks considered 'everyday', while $38.8 \%$ of the total energy packed within the lunchbox was provided by discretionary foods and drinks, as classified according to the Australian Dietary Guidelines. Energy, percentage of energy from 'everyday' and discretionary foods and number of 'everyday' and discretionary servings in school lunchboxes are detailed in Table 3.

\section{Number of servings of discretionary foods in school lunchboxes}

At least one serving of discretionary foods was found in $85 \%$ of lunchboxes, with $25 \%$ of children's lunchboxes containing at least four servings of discretionary foods. Children who had no servings of discretionary foods, packing only 'everyday' foods, accounted for only $12 \%$ of lunchboxes. There were no significant differences in sex, SES and BMI between those who had no servings of discretionary foods in their lunchbox and those who had more than one discretionary choice. However, the odds of a lunchbox having no discretionary foods decreased as the child's age increased (OR $=0.90,95 \%$ CI $0 \cdot 8,1 \cdot 0$, $P<0.01)$. The number of discretionary servings in the school lunchbox is detailed in Fig. 1.

\section{Associations between child characteristics and foods packed in lunchboxes}

There were no significant interactions between sex, SES, BMI and school year. Younger children in Kindergarten-Grade 2 had significantly more food items in their lunchbox compared with older children in Grades 3-6 (5.1 v. 4.7 items, $P<0 \cdot 01)$. There was, however, no significant difference in the total number of food servings by age. Younger children were also more
Table 2 Food and drink items in lunchboxes of the sample of Kindergarten-Grade 6 primary-school students ( $n$ 1769) from twelve Catholic primary schools located in the Hunter region of New South Wales, Australia, February to March 2017

\begin{tabular}{|c|c|c|}
\hline SFC food or drink category & $n$ & $\begin{array}{l}\% \text { of lunchboxes } \\
\text { containing the item }\end{array}$ \\
\hline \multicolumn{3}{|l|}{ Main } \\
\hline Bread $^{*}$ & 1446 & $81 \cdot 0$ \\
\hline Fast food & 101 & $5 \cdot 7$ \\
\hline Leftovers/mixed dishes* & 83 & $4 \cdot 7$ \\
\hline \multicolumn{3}{|l|}{ Snacks } \\
\hline Fruit $^{\star}$ & 1532 & $85 \cdot 8$ \\
\hline Muesli and/or fruit bars & 533 & $29 \cdot 8$ \\
\hline $\begin{array}{l}\text { Cheese, eggs, dried fruit, } \\
\text { nuts and dips }{ }^{\star}\end{array}$ & 444 & $24 \cdot 9$ \\
\hline Savoury biscuits & 415 & $23 \cdot 2$ \\
\hline $\begin{array}{l}\text { Cakes, muffins, slices, pastries, } \\
\text { doughnuts and tarts }\end{array}$ & 403 & $22 \cdot 6$ \\
\hline Crisps & 381 & $21 \cdot 3$ \\
\hline Vegetables* & 361 & $20 \cdot 2$ \\
\hline Chocolate biscuits & 329 & $18 \cdot 4$ \\
\hline Sweet biscuits & 301 & $16 \cdot 9$ \\
\hline Rice or water crackers* & 235 & $13 \cdot 2$ \\
\hline Extruded snacks & 233 & $13 \cdot 1$ \\
\hline Yoghurt $^{\star}$ & 226 & $12 \cdot 7$ \\
\hline Chocolates and lollies & 198 & $11 \cdot 1$ \\
\hline Popcorn* & 184 & $10 \cdot 3$ \\
\hline Rice cakes* & 132 & 7.4 \\
\hline Pretzels & 71 & $4 \cdot 0$ \\
\hline Crispbreads* & 52 & 2.9 \\
\hline Processed meat & 51 & $2 \cdot 9$ \\
\hline 'Everyday’ buns” & 39 & $2 \cdot 2$ \\
\hline $\begin{array}{l}\text { Discretionary miscellaneous } \\
\text { items }\end{array}$ & 35 & $2 \cdot 0$ \\
\hline Pikelets (small pancakes) ${ }^{\star}$ & 32 & $1 \cdot 8$ \\
\hline Noodles & 25 & 1.4 \\
\hline Discretionary buns & 23 & $1 \cdot 3$ \\
\hline Refined cereals & 19 & $1 \cdot 1$ \\
\hline Baked beans or legumes* & 14 & 0.8 \\
\hline Bread $^{*}$ & 17 & $1 \cdot 0$ \\
\hline Dairy dessert & 15 & 0.8 \\
\hline Fast-food snacks & 14 & $0 \cdot 8$ \\
\hline Butter popcorn & 14 & 0.8 \\
\hline Custards* & 13 & 0.7 \\
\hline Fruit jelly & 10 & 0.6 \\
\hline Tuna* & 10 & 0.6 \\
\hline Wholegrain cereals* & 9 & 0.5 \\
\hline 'Everyday' miscellaneous` & 8 & 0.5 \\
\hline Scone* ${ }^{*}$ & 6 & 0.3 \\
\hline Cheese and bacon roll & 2 & 0.1 \\
\hline \multicolumn{3}{|l|}{ Drinks } \\
\hline Water* & 1205 & $67 \cdot 5$ \\
\hline Juice or cordial & 257 & 14.4 \\
\hline $\begin{array}{l}\text { Milk full-fat or fortified milk } \\
\text { drink }^{*}\end{array}$ & 49 & $2 \cdot 7$ \\
\hline
\end{tabular}

SFC, School Food Checklist.

*Items classified as an 'everyday' food or drink.

likely to have a higher number of 'everyday' food servings ( $3.3 v \cdot 3 \cdot 0$ servings, $P<0.01)$ and a higher percentage of energy from 'everyday' foods $(63.7 v .58 .1 \%, P<0.01)$. Older children had a higher percentage of energy from discretionary foods (39.1 v. 33.8\%, $P<0.01)$ than younger children. There was no statistically significant difference in servings of discretionary foods, or total mean kilojoule content, by school year or sex. The percentage of 
Table 3 Energy content of foods from school lunchboxes of the sample of Kindergarten-Grade 6 primary-school students ( $n$ 1769) from twelve Catholic primary schools located in the Hunter region of New South Wales, Australia, February to March 2017

\begin{tabular}{|c|c|c|c|c|c|c|c|c|}
\hline & \multicolumn{2}{|c|}{ Energy $(\mathrm{kJ})$} & \multirow{2}{*}{$\begin{array}{l}\% \text { of total energy } \\
\text { from 'everyday' } \\
\text { foods and drinks }\end{array}$} & \multirow{2}{*}{$\begin{array}{l}\% \text { of total energy } \\
\text { from discretionary } \\
\text { foods and drinks }\end{array}$} & \multicolumn{2}{|c|}{$\begin{array}{l}\text { Number of } \\
\text { 'everyday' food } \\
\text { servings }\end{array}$} & \multicolumn{2}{|c|}{$\begin{array}{c}\text { Number of } \\
\text { discretionary food } \\
\text { servings }\end{array}$} \\
\hline & Mean & SD & & & Mean & SD & Mean & SD \\
\hline All participants & 2748 & 882 & $61 \cdot 2$ & $38 \cdot 8$ & $3 \cdot 1$ & 1.6 & 2.5 & $2 \cdot 1$ \\
\hline \multicolumn{9}{|l|}{ Sex } \\
\hline Female & 2714 & 886 & $60 \cdot 7$ & $37 \cdot 1$ & $3 \cdot 2$ & 1.6 & $2 \cdot 4$ & 1.9 \\
\hline Male & 2770 & 870 & $60 \cdot 3$ & $36 \cdot 6$ & $3 \cdot 1$ & 1.6 & $2 \cdot 5$ & $2 \cdot 3$ \\
\hline$P$ value & \multicolumn{2}{|c|}{0.13} & 0.55 & 0.87 & \multicolumn{2}{|c|}{0.21} & \multicolumn{2}{|c|}{0.12} \\
\hline \multicolumn{9}{|l|}{ School year } \\
\hline Kindergarten-Grade 2 & 2777 & 880 & $63 \cdot 7$ & $33 \cdot 8$ & $3 \cdot 3$ & $1 \cdot 6$ & 245 & $2 \cdot 1$ \\
\hline Grades 3-6 & 2725 & 883 & $58 \cdot 1$ & $39 \cdot 1$ & 3.0 & 1.6 & 2.6 & $2 \cdot 1$ \\
\hline$P$ value & \multicolumn{2}{|c|}{0.29} & $<0.01$ & $<0.01$ & \multicolumn{2}{|c|}{$<0.01$} & \multicolumn{2}{|c|}{0.07} \\
\hline \multicolumn{9}{|l|}{ Socio-economic status ${ }^{*}$} \\
\hline Most disadvantaged & 2842 & 903 & 59.5 & $37 \cdot 6$ & $3 \cdot 2$ & 1.7 & $2 \cdot 6$ & $2 \cdot 2$ \\
\hline Least disadvantaged & 2536 & 793 & 62.9 & 34.8 & 2.99 & 1.4 & $2 \cdot 2$ & 1.8 \\
\hline$P$ value & \multicolumn{2}{|c|}{0.03} & 0.22 & 0.54 & \multicolumn{2}{|l|}{0.03} & \multicolumn{2}{|c|}{0.83} \\
\hline \multicolumn{9}{|l|}{$\mathrm{BMI}$} \\
\hline Underweight/healthy & 2711 & 855 & $59 \cdot 7$ & $37 \cdot 6$ & 3.0 & 1.6 & 2.5 & $2 \cdot 0$ \\
\hline Overweight/obese & 2775 & 904 & 58.6 & $38 \cdot 1$ & 3.1 & 1.5 & $2 \cdot 5$ & $2 \cdot 1$ \\
\hline$P$ value & \multicolumn{2}{|c|}{0.55} & 0.87 & 0.96 & \multicolumn{2}{|c|}{0.60} & \multicolumn{2}{|c|}{0.80} \\
\hline
\end{tabular}

Significant $P$ values are indicated in bold.

*Socio-economic status based on the 2016 Socio-Economic Index for Areas (SEIFA) Index of Relative Socio-Economic Advantage/Disadvantage. Most disadvantaged = lowest quartiles of SEIFA; least disadvantaged $=$ highest quartiles of SEIFA.

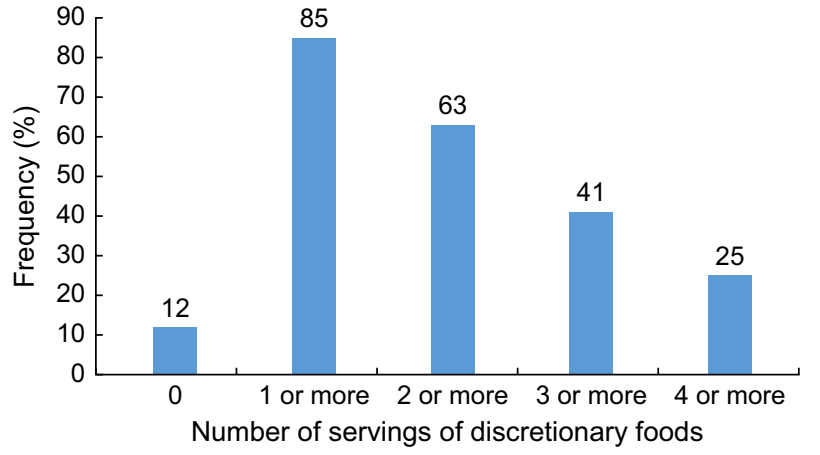

Fig. 1 (colour online) Distribution of the number of servings of discretionary foods in the lunchbox of Kindergarten-Grade 6 primary-school students ( $n$ 1769) from twelve Catholic primary schools located in the Hunter region of New South Wales, Australia, February to March 2017

energy from 'everyday' and discretionary foods was not significantly different between children in different BMI categories.

Children who were the most socio-economically disadvantaged had significantly higher kilojoules in their school lunchbox compared with the least disadvantaged students (2842 v. $2536 \mathrm{~kJ}, P=0.03$ ). However, the most disadvantaged students had a significantly higher number of 'everyday' foods servings in their lunchbox than those with the least disadvantage ( $3.2 v .3 .0$ servings, $P=0.03$ ). There was no statistically significant difference in the percentage of energy from 'everyday' or discretionary foods by SES.

\section{Discussion}

The present study updates data published more than a decade ago $^{(11)}$ assessing the total lunchbox content, mean kilojoule content and proportion of lunchboxes containing 'everyday' and discretionary foods within primary-school children's lunchboxes. The study highlights considerable opportunities to improve the nutritional quality of foods packed for children in school lunchboxes, with the vast majority of primary-school lunchboxes (85\%) containing discretionary foods and two-thirds (63\%) of lunchboxes containing at least two servings of discretionary foods. Lunchboxes containing only foods consistent with Australian Dietary Guidelines were in the minority, representing just over $10 \%$ of those observed.

The findings suggest that the majority of children, irrespective of age or weight status, may be consuming above the upper limit of discretionary servings recommended by the Australian Dietary Guidelines within school hours alone. The Australian Guide to Healthy Eating recommends younger children up to 8 years old should avoid or limit discretionary choices to no more than half a serving per day unless the child is taller or more active, in which case the child can consume up to two servings per day ${ }^{(8)}$. Older children and adolescents who are active and within the healthy weight range may consume up to $2 \cdot 5-3$ servings of discretionary choices or additional 'everyday' foods per day ${ }^{(8)}$. Given discretionary food intake is a risk factor for unhealthy weight gain, the findings suggest that interventions targeting the packing of discretionary foods for child consumption at school are 
warranted and have the potential to yield important improvements in child public health nutrition and preventing unhealthy weight gain.

The high number of discretionary foods contained within lunchboxes was consistent with findings from other studies reporting on the nutritional content of school lunchboxes conducted more than a decade ago. Brennan et al. highlighted that a large proportion of children had one or more 'extras' packed in their lunchbox ${ }^{(12)}$. Sanigorski et al. reported that over $50 \%$ of children had 2-4 servings of 'junk food' and only $7 \%$ of children had no servings of 'junk food' in their school lunchbox ${ }^{(11)}$. Sanigorski et al. also reported that younger children consumed a higher proportion of cakes, sweet spreads and desserts than older children, which was not found in our study ${ }^{(11)}$. Similarly, Evans et al. conducted a study in the UK and reported that only $8 \%$ of lunchboxes contained no confectionery, savoury (discretionary) snacks and sweetened drinks, with over $40 \%$ of children having both confectionery and savoury snacks packed in the lunchbox ${ }^{(13)}$. While broadly there appears little improvement in the nutritional quality of foods packed in students' lunchboxes over the past 10 years, there is evidence to suggest that there has been a reduction in the packing of sweetened drinks over that period. In our study $14.39 \%$ of drinks in school lunchboxes were sweetened drinks compared with $34 \%$ reported by Sanigorski et al. in their 2003-2004 study ${ }^{(11)}$.

Fruit was the snack most frequently provided in the lunchbox, findings that may reflect the success of an existing population-based initiative targeting schools in the region and across New South Wales in general ('Crunch and Sip') which targets school vegetable and fruit breaks ${ }^{(18)}$. However, $79 \%$ of children did not pack any vegetables within the lunchbox. Without consuming vegetables during school hours, up to five servings of vegetables would have to be consumed before and after school in order to meet recommendations of the Australian Guide to Healthy Eating - a proposition that is unlikely, given existing data on intake of vegetables within the home environment ${ }^{(24)}$. As lunchboxes appear characterised by excessive discretionary foods and limited availability of vegetables, interventions that seek to substitute the packing of discretionary food items with vegetables or vegetable-based items may be particularly effective in improving the nutritional content of children's lunchboxes.

There were relatively few differences in the energy or nutritional quality of foods packed for children by demographic, SES or weight status characteristics. Despite children in Kindergarten to Grade 2, on average, having lower daily energy requirements than those in Grades 3 to $6^{(8)}$, there was no statistically significant difference in total energy of the lunchbox or the number of discretionary food servings between school years. This may be due to younger children tending to have more food items in their lunchbox and more 'everyday' food servings than children in Grades 3-6, creating particular risks for unhealthy weight gain among children of this age. There was a decline, however, in the nutritional value of children's lunchboxes, with the percentage of lunchbox energy from discretionary foods being higher among older children and accounting for $39 \%$ of total lunchbox energy. This may have occurred with the increased independence and involvement of older children in the packing of lunchboxes and their strong preferences for discretionary food items ${ }^{(25)}$. Furthermore, in the past decade, there has been increased emphasis on developing nutrition guidelines and policies guiding the provision of foods within the early childcare and pre-school setting ${ }^{(26)}$. The presence of such policies in the early years may also influence the types of foods packed by parents once entering the school environment. Finally, while children from more disadvantaged backgrounds were more likely to pack everyday foods, these lunchboxes also had a higher total kilojoule content, with a mean difference of $300 \mathrm{~kJ}$. However, this is likely to be attributed, in part, to the increased provision of servings of healthy foods in these children's lunchboxes. This finding warrants further investigation as evidence from Australia, the UK and the USA has indicated a significant positive association between poor diet quality and $\mathrm{SES}^{(27)}$. While some opportunity for tailoring among population groups exists, by and large the findings suggest that the contents of the school lunchbox is a populationbased problem affecting a diverse range of children of primary-school age. In the last decade there has been a significant increase in the number of lunchbox products that have been specifically designed for the school lunchbox. While there are a number of regulations manufacturers must follow in the labelling of foods, there are currently no mandates or encouragement given to manufacturers in providing smaller portions of discretionary foods in Australia, to reduce the consumption of discretionary food products in the diet. This only highlights the need for public health interventions to reduce the purchasing of discretionary food products for the school lunchbox.

Strengths of the present study include the use of direct and objective observation, in addition to the use of validated tools, including the SFC to assess and analyse lunchbox contents. The SFC was designed for the Australian context, was completed by trained research assistants and was analysed by dietitians, enhancing the validity of results. Nevertheless, the study findings should be considered in the context of its limitations. Comprehensive assessment of dietary intake of children across the entire day is required to assess the relative impact of school lunchboxes on child dietary risks. The analysis of the overall diet of children will assist in determining consumption patterns in relation to dietary guidelines. Second, the present study did not assess or ask students about any 
foods purchased from the school canteen, which may affect results, being indicative of overall food consumed during school hours. Third, the study was conducted in one geographical region which limits the generalisability of findings. The study focused only on foods packed within school lunchboxes and did not assess student consumption of lunchbox foods or wastage. As no formal school policies exist regarding teacher supervision which encourages consumption of healthier foods or teacher role modelling, further assessment is warranted to determine if the amount of food packed for children is consumed while at school or becomes food waste. Furthermore, while a validated tool was used to collect population-level lunchbox data, some measurement error is inherent when measuring dietary intake data. Further, small amounts of missing data occurred which may result in a risk of biased results.

There is currently little known about the parental and child barriers to packing lunchboxes that are in line with dietary guidelines. The development of school policies and population-based strategies to support parents overcome barriers to packing healthy lunchboxes are warranted. There is an urgent need for suitable interventions likely to impact on energy balance and nutritional quality of primary-school children's lunchboxes. This has the capacity to reduce the risk of childhood obesity and improve overall nutrition of children, which is considered a health priority in Australia and internationally.

\section{Acknowledgements}

Financial support: The work was supported by Hunter Medical Research Institute (HMRI), Hunter Children's Research Foundation (HCRF) and Hunter New England Population Health. R.S. is supported by a National Health and Medical Research Council (NHMRC) TRIP Fellowship (grant number APP1150661); N.N. is supported by an NHMRC TRIP Fellowship (grant number APP1132450) and a Hunter New England Clinical Research Fellowship; S.Y. is supported by the Australian Research Council Discovery Early Career Research Award (grant number DE170100382); LW is supported by an NHMRC Career Development Fellowship (grant number APP1128348), a Heart Foundation Future Leader Fellowship (grant number 101175) and a Hunter New England Clinical Research Fellowship. Funders had no role in the design, analysis or writing of this article. Conflict of interest: None. Authorship: R.S., N.N. and L.W. conceived of and designed the study. R.S., N.N., S.Y., K.G., L.J. and C.D. designed the intervention. V.H. provided cultural advice. R.S., N.N., R.R. and A.W. undertook data collection. R.R., A.W. and A.B. assisted with data cleaning. C.L. led statistical analysis. R.S. and A.B. drafted the manuscript, with all other co-authors contributing to drafts of the paper. All authors accept full responsibility for, and have read and approved, the final manuscript. Ethics of human subject participation: This study was conducted according to the guidelines laid down in the Declaration of Helsinki and approval to conduct this study was obtained from Hunter New England Human Research Ethics Committee (reference number $06 / 07 / 26 / 4.04$ ), the University of Newcastle (reference number H-2008-0343) and the Maitland Newcastle Catholic Schools Office. Written informed consent was obtained from all subjects.

\section{References}

1. Abarca-Gómez L, Abdeen ZA, Hamid ZA et al. (2017) Worldwide trends in body-mass index, underweight, overweight, and obesity from 1975 to 2016 : a pooled analysis of 2416 population-based measurement studies in 128.9 million children, adolescents, and adults. Lancet 390, 2627-2642.

2. Hardy L, Mihrshahi S, Drayton B et al. (2016) NSW Schools Physical Activity and Nutrition Survey (SPANS) 2015: Full Report. Sydney, NSW: Department of Health.

3. Maynard M, Gunnell D, Emmett P et al. (2003) Fruit, vegetables, and antioxidants in childhood and risk of adult cancer: the Boyd Orr cohort. J Epidemiol Community Health 57, 218-225.

4. Lifshitz F (2008) Obesity in children. J Clin Res Pediatr Endocrinol 1, 53-60.

5. Bell AC \& Swinburn BA (2004) What are the key food groups to target for preventing obesity and improving nutrition in schools? Eur J Clin Nutr 58, 258-263.

6. Bates B, Cox L, Nicholson S et al. (2016) National Diet and Nutrition Survey. Results from Years 5 and 6 (combined) of the Rolling Programme (2012/2013-2013/ 2014). https://www.gov.uk/government/uploads/system/ uploads/attachment_data/file/551352/NDNS_Y5_6_UK_ Main_Text.pdf (accessed November 2019).

7. US Department of Health and Human Services \& US Department of Agriculture (2015) Shifts needed to align with healthy eating patterns. In 2015-2020 Dietary Guidelines for Americans. http://health.gov/dietaryguidelines/2015/ guidelines/chapter-2/a-closer-look-at-current-intakes-andrecommended-shifts/ (accessed November 2019).

8. National Health and Medical Research Council (2013) Australian Dietary Guidelines. Canberra, ACT: NHMRC.

9. Dunford EK \& Popkin BM (2018) 37 year snacking trends for US children 1977-2014. Pediatr Obes 13, 247-255.

10. Wolfenden L, Falkiner M \& Bell C (2010) Addressing the burden of obesity among disadvantaged families. Dev Prac Child Youth Family Work 25, 11-20.

11. Sanigorski AM, Bell AC, Kremer PJ et al. (2005) Lunchbox contents of Australian school children: room for improvement. Eur J Clin Nutr 59, 1310-1316.

12. Brennan L, Miles CL, Mitchell S et al. (2010) Changes in the content of children's school lunches across the school week. Health Promot J Aust 21, 196-201.

13. Evans CE, Greenwood DC, Thomas JD et al. (2010) A cross-sectional survey of children's packed lunches in the UK: food- and nutrient-based results. I Epidemiol Community Health 64, 977-983.

14. Australian Bureau of Statistics (2012) Population Estimates (HOIST). Sydney, NSW: NSW Ministry of Health. 
15. University of Bern (2007) STROBE Statement - Checklist of Items that Should be Included in Reports of CrossSectional Studies. Bern: University of Bern; available at https://www.strobe-statement.org/fileadmin/Strobe/uploads/ checklists/STROBE_checklist_v4_cross-sectional.pdf (accessed November 2019).

16. Sutherland R, Campbell E, Lubans DR et al. (2013) A cluster randomised trial of a school-based intervention to prevent decline in adolescent physical activity levels: study protocol for the 'Physical Activity 4 Everyone' trial. BMC Public Health $13,57$.

17. Sutherland RL, Campbell EM, Lubans DR et al. (2016) The Physical Activity 4 Everyone cluster randomized trial: 2-year outcomes of a school physical activity intervention among adolescents. Am J Prev Med 51, 195-205.

18. Nathan N, Wolfenden L, Butler M et al. (2011) Vegetable and fruit breaks in Australian primary schools: prevalence, attitudes, barriers and implementation strategies. Health Educ Res 26, 722-731.

19. Kremer PJ, Bell AC \& Swinburn BA (2006) Calibration and reliability of a school food checklist: a new tool for assessing school food and beverage consumption. Asia Pac J Clin Nutr 15, 465-473.

20. Mitchell SA, Miles CL, Brennan L et al. (2010) Reliability of the school food checklist for in-school audits and photograph analysis of children's packed lunches. J Human Nutr Diet 23, 48-53.

21. Australian Bureau of Statistics (2001) Technical Paper: Census of Population and Housing: Socio-Economic Indexes for Australia (SEIFA). Canberra, ACT: Commonwealth of Australia.
22. Stewart A, Marfell-Jones M \& International Society for the Advancement of Kinanthropometry (2011) International Standards for Anthropometric Assessment. Lower Hutt: ISAK.

23. Cole TJ, Bellizzi MC, Flegal KM et al. (2000) Establishing a standard definition for child overweight and obesity worldwide: international survey. BMJ 320, 12401243.

24. Australian Bureau of Statistics (2016) Vegetables and legumes/ beans. In 4364.0.55.012 - Australian Health Survey: Consumption of Food Groups from the Australian Dietary Guidelines, 2011-12. Canberra, ACT: Commonwealth of Australia; available at http://www.abs.gov.au/ausstats/ abs@.nsf/Lookup/by\%20Subject/4364.0.55.012 2011-12 Main\%20Features Vegetables,\%20legumes\%20and\%20 beans 10 (accessed November 2019).

25. Reicks M, Banna J, Cluskey M et al. (2015) Influence of parenting practices on eating behaviors of early adolescents during independent eating occasions: implications for obesity prevention. Nutrients 7, 8783-8801.

26. Seward K, Wolfenden L, Finch M et al. (2018) Improving the implementation of nutrition guidelines in childcare centres improves child dietary intake: findings of a randomised trial of an implementation intervention. Public Health Nutr 21, 607-617.

27. Manyanga T, Tremblay MS, Chaput JP et al. (2017) Socioeconomic status and dietary patterns in children from around the world: different associations by levels of country human development? BMC Public Health 17, 457 . 